\title{
Uwarunkowane kulturowo zmiany językowe w kaszubskim przekładzie Bajki o rybaku i rybce Aleksandra Siergiejewicza Puszkina
}

$\mathrm{Na}$ interferencje między językiem a kulturą zwracał uwagę Benjamin Lee Whorf, który twierdził, że każdy system językowy determinuje wzorce kulturowe (Whorf 2002, s. 337). W odniesieniu do hipotezy Sapira-Whorfa o oddziaływaniu języka na postrzeganie świata oraz na zachowania kulturowe formułowano tezy o nieprzekładalności językowej. Odmienność kulturowa różnych wspólnot etnicznych czy też narodowych może warunkować problemy natury językowej tożsame z nieprzetłumaczalnością pewnych elementów określonego języka na inny język; oznacza to, że nieprzekładalność kulturowa może implikować nieprzekładalność językową (Kielar 1988, s. 87). Dokonując przekładu jakiejś wypowiedzi językowej, jednocześnie przenosimy tę wypowiedź w inną kulturę. Stąd też zadaniem tłumacza jest nie tylko przekładanie jednostek językowych, lecz także przyswojenie w translacji obcych elementów kulturowych — obecnych w pierwowzorze. Autor thumaczenia jest pośrednikiem w transferze kultury (Krysztofiak 2011, s. 56-57). Zabiegi translatorskie, mające na celu przekład kulturowy, zasadniczo są ukierunkowane albo w stronę adaptacji, czyli pozbawienia tekstu sygnałów obcości, albo w stronę egzotyzacji, czyli takiego sposobu tłumaczenia, w którym nośniki obcości są obecne (Lewicki 2000, s. 143-153). Tłumacz, dokonując wyboru między strategią adaptacji i egzotyzacji, musi liczyć się ze stanem wiedzy językowej i pozajęzykowej swoich potencjalnych czytelników. W szczególności strategia adaptacji wymaga dobrej intuicji thumacza, ponieważ całkowite przystosowanie utworu do warunków własnej kultury i predyspozycji odbiorców może doprowadzić do sytuacji, że dzieło będzie nie translacją, ale utworem adaptowanym lub swobodną translatorską parafrazą pierwowzoru.

$\mathrm{W}$ niniejszym artykule zajmę się kulturowo uwarunkowanymi zmianami językowymi, odnotowanymi w kaszubskim przekładzie Bajki o rybaku i rybce 
Aleksandra Siergiejewicza Puszkina. Rosyjski utwór jest upoetycznioną wersją niemieckiej baśni braci Grimm. Dzieło to z rosyjskiego oryginału na język kaszubski ${ }^{1}$ przełożył dziewiętnastowieczny pisarz, twórca kaszubszczyzny literackiej i tłumacz, Florian Ceynowa. Translacja bajki Puszkina na język kaszubski ukazała się w 1868 roku w IX numerze wydawanego przez samego Ceynowę czasopisma, zatytułowanego „Skôrb Kaszébsko-słovjnskjé mòvé” i miała ona tytuł Wò rébôku é ribce (Ceynowa 1986, s. 128-132).

Pojawiające się pod wpływem kulturowym zmiany językowe, rejestrowane w przekładzie Bajki o rybaku i rybce na język kaszubski, w zasadzie mieszczą się w zakresie dwóch problemów: przesunięć znaczeniowych słów i wyrażeń oraz znalezienia ekwiwalentów dla frazeologizmów. Te ostatnie, jak wiadomo, z zasady silnie zakorzenione są w kulturze społeczności używającej danego języka.

Przesunięcia semantyczne bądź też zmiany słów i wyrażeń są stosunkowo częste w przekładach literackich, wszak w thumaczeniach tekstów artystycznych nie przywiązuje się tak wielkiej wagi do precyzji, jak np. w przekładach naukowych czy specjalistycznych. Zmiany znaczeń mogą mieć różne przyczyny; mogą być motywowane staraniami tłumacza, aby utrzymać rytm w utworze poetyckim, mogą też wynikać z niekompetencji autora translacji i nieznajomości przez niego odpowiedniego ekwiwalentu słowa czy wyrażenia w języku docelowym. Jednak zmiany znaczeń mogą być też związane z niejednakowymi kodami kulturowymi. Kulturowe symbole jednej grupy etnicznej czy narodowej nie zawsze są rozpoznawalne dla przedstawicieli innych kultur. Różnice kulturowe często związane są $\mathrm{z}$ niewystępowaniem $\mathrm{w}$ języku docelowym odpowiedników niektórych słów czy wyrażeń. W niniejszym artykule skupię się tylko na tych przykładach przesunięć znaczeniowych, które są motywowane kulturowo, pominę natomiast te przykłady zmian semantycznych słów i wyrażeń, które wynikały z niekompetencji tłumacza lub miały na celu utrzymanie rytmiki wiersza tonicznego w kaszubskojęzycznej wersji bajki.

Kaszubski tłumacz poszukiwał ekwiwalentów notowanych w pierwowzorze wyrazów, które są nazwami noszonej przez lud rosyjski odzieży. W oryginale $B a j$ ki o rybaku i rybce odnotowana została forma кичка (107 wers) - wyraz ten jest silnie zakorzeniony w kulturze Rosji i nie ma ekwiwalentu w wielu innych językach. Кичка, znana też pod nazwą кика, jest żeńskim ludowym nakryciem głowy, mającym postać otwartej korony, które znane było już w kulturze staroruskiej; pierwsze poświadczenie nazwy tej części ubioru pochodzi z 1328 roku. Cechą charakterystyczną tego elementu garderoby było to, że miał on rogi u góry. Formę rogów uzyskiwano dzięki wykorzystaniu materiałów takich, jak np. kora brzozy. Кичка wykonana była z płótna, do którego często przyszyte były ozdobne perły, koraliki i drogocenne kamienie. Nazwy кичка, кика mogły albo odnosić

${ }^{1}$ Trzeba nadmienić, że omawiany tu utwór został także przetłumaczony na język polski przez Juliana Tuwima oraz przez Władysława Sebyłę. 
się do całego tego nakrycia głowy, albo niekiedy określano nimi jedynie dolną jego część, przykrywającą włosy. Кикa nazywana była także „koroną zamążpójścia" i pierwotnie zgodnie ze starym zwyczajem miała ją zakładać panna młoda, a w późniejszym czasie zakładały ją kobiety zamężne. W XIX wieku кика noszona była w Rosji przez duchowieństwo. Natomiast w XX wieku tę część ubioru można było spotkać jeszcze w niektórych regionach na południu Rosji, a później została ona zastąpiona chustą albo lnianą czapką całkowicie zakrywającą włosy, splecione w dwa warkocze, często zdobioną koronką, znaną jako повойник (Андреева 1997, s. 196).

W kulturze kaszubskiej nie ma przedmiotu odpowiadającego rosyjskim nazwom кичка, кика, jest to element ubioru silnie i wieloaspektowo wpisany w tradycyjną ludową kulturę rosyjską, jednak kontekst, w którym rzeczownik кичка pojawił się w pierwowzorze bajki Puszkina, pozwolił kaszubskiemu thumaczowi odnieść się do innego nakrycia głowy, znanego w kulturze kaszubskiej. W rosyjskojęzycznym oryginale pojawił się obraz staruszki stojącej na ganku, która ma na głowie nakrycie określone jako кичка, wykonane z brokatu, czyli grubej jedwabnej tkaniny z wypukłym haftowanym wzorem, wyszywanym złotą czy srebrną nitką. Ceynowa całą tę scenerię przeniósł do kaszubskich realiów, posługując się przy tym strategią adaptacji. Elementy rosyjskiej kultury, które nie byłyby rozpoznawalne dla kaszubskiego czytelnika, zostały przez thumacza zastąpione ekwiwalentnymi rodzimymi kaszubskimi realiami. W kaszubskojęzycznej wersji Bajki o rybaku i rybce staruszka siedzi na schodach i ma na głowie złotą hùlkę. Co prawda kaszubska tradycyjna hùlka - inaczej niż zostało to odnotowane w tłumaczeniu Ceynowy - jest biała, nie złota, lecz tłumacz częściowo chciał przystosować tłumaczenie do kolorytu lokalnego, odwołując się do przepychu, bogactwa i kosztowności materiału, z jakiego zrobiona jest tradycyjna rosyjska кичка. Forma hùlka obecnie w samej kaszubszczyźnie jest już archaizmem wyrazem przestarzałym, a także przedmiot, do którego się ta nazwa odnosi, nie jest już używany na Kaszubach; Bernard Sychta w Słowniku gwar kaszubskich na tle kultury ludowej odnotował przy haśle hulka ${ }^{2}$ dwa krzyżyki, co znaczy, że wyraz w momencie jego zapisywania wyszedł już całkowicie z użycia (Sychta 1965-1976, t. II, s. 16). Należy jednak pamiętać, że tłumaczenie bajki Puszkina wykonywane było w XIX wieku i wówczas zarówno wyraz hùlka, jak i jego desygnat były znane Kaszubom i to nakrycie głowy było na Kaszubach — podobnie jak w Rosji кичка — symbolem zamążpójścia, znany jest nawet kaszubski frazeologizm jic pòd czepc odnoszący się do wyjścia za mąż (Sychta 1965-1976, t. I, s. 167). Hùlka była białym, noszonym przez kobiety czepkiem, okrągłym, krochmalonym i zmarszczonym dookoła głowy (Sychta 1965-1976, t. II, s. 16). Fakt powiązania zarówno rosyjskiej кички, jak i kaszubskiej hùlki z zamążpójściem

\footnotetext{
2 Pisownia oryginalna Sychty, zgodnie ze współczesną kaszubską ortografią: hùlka.
} 
jest motywem, który z pewnością skłonił Floriana Ceynowę do użycia tego, a nie innego wyrazu w kaszubskojęzycznym tłumaczeniu bajki.

W oryginalnym rosyjskim tekście Bajki o rybaku i rybce pojawiła się jeszcze jedna nazwa elementu garderoby, która nie ma ekwiwalentu w kaszubszczyźnie. Użyta przez Puszkina forma душегрейка (106 wers), oznaczająca to samo, co душегрея, odnosi się do ubrania noszonego w kulturze staroruskiej, mianowicie od XV do XVIII wieku. Była to krótka, ciepła odzież żeńska, zazwyczaj uszyta z tkaniny brokatowej lub aksamitnej, zdobiona perłami i haftem, bez zapięcia i zwykle bez rękawów, z tyłu ułożona w fałdy. Ten staroruski kobiecy ubiór był prototypem współczesnych kamizelek (Андреева 1997, s. 160). W rosyjskim pierwowzorze Bajki o rybaku i rybce stojąca na ganku staruszka na ramionach ma odzienie określone przez Puszkina jako дорогая соболья душегрейка. W kaszubszczyźnie nie ma ani językowego, ani kulturowego ekwiwalentu tego elementu ubioru, dlatego Florian Ceynowa również w przypadku przekładania nazwy tej części odzieży odwołał się do strategii adaptacji. W kaszubskojęzycznej wersji utworu staruszka jest w drogjm sobolim kòzuszku. Co prawda na Kaszubach ludzie nie noszą kożuszków wykonanych ze skóry sobola, jak ma to miejsce w Rosji, jednak tłumacz częściowo zdecydował się utrzymać ten lokalny rosyjski koloryt. Kaszubski kòzuszk (w dzisiejszej pisowni: kòzuszk) - nazwa użyta w translacji wykonanej przez Ceynowę — jest tym samym, co polski kożuszek czy rosyjski тулупчик, tak więc mamy do czynienia z przesunięciem znaczeniowym wyrazu, a także z przesunięciem kulturowym. Element tradycyjnej rosyjskiej mody, jakim jest душегрейка, w kaszubskojęzycznej translacji został wyeliminowany na rzecz bardziej uniwersalnego, niezwiązanego z konkretną kulturą kożuszka.

Kolejnymi nazwami, które ze względu na odmienną kulturę nie mają ekwiwalentów w języku kaszubskim, są słowa i wyrażenia związane z państwem rosyjskim oraz władcami nim rządzącymi. Carowie rządzili w Rosji do 1917 roku, tytuł ten znany był nie tylko na terenach rosyjskich, lecz także w innych państwach, kontynuujących tradycję bizantyjską. Kaszubszczyzna, znajdująca się na peryferiach Polski, nigdy nie wytworzyła odrębnej jednostki leksykalnej dla określenia władców tych państw. $Z$ tego też względu odnotowana w pierwowzorze forma царица (wersy: 123, 143, 176, 193) nie otrzymała zupełnie adekwatnego thumaczenia na język kaszubski; Florian Ceynowa przetłumaczył ten rzeczownik jako królova, czyli adaptował ją do wiedzy i kultury kaszubskiej, znajdującej się w ramach państwa polskiego, gdzie niemal do końca XVIII wieku rządzili królowie, a potem jeszcze w XIX wieku cesarzowie Rosji tytułowali się także królami Polski.

Również rosyjska nazwa państwa uрарство, thumaczona na język polski jako carstwo, nie była znana ludowi kaszubskiemu. Została ona zarejestrowana w pierwowzorze Bajki o rybaku i rybce (127 wers). Tłumacz kaszubski także w tym przypadku posłużył się strategią adaptacji i, przyswajając tę nazwę do kultury i wiedzy Kaszubów, przetłumaczył ją jako królestvo. Przymiotnik utworzony od 
rosyjskiego rzeczownika ųap, mianowicie wyraz ųарскиŭ, nie został w tekście przekładu zapożyczony $\mathrm{z}$ języka rosyjskiego, ale tłumacz również tę nazwę adaptował do stanu wiedzy i rodzimej kultury ludu kaszubskiego; otóż w oryginale bajki Puszkina pojawiło się wyrażenie ц̧арские палать (148 wers), które zostało przetłumaczone przez Ceynowę jako krolevskj pałac.

Natomiast odnotowany w pierwowzorze bajki Puszkina rzeczownik государыня (wersy: 49, 71, 96, 140, 191), oznaczający osobę płci żeńskiej zarządzającą państwem, także nie znalazł bezpośredniego ekwiwalentu w języku kaszubskim. Kaszubszczyzna nie ma rozbudowanej terminologii dotyczącej nazywania osób rządzących w państwie, co poniekąd wynika z historii tego regionu, Kaszuby nie są odrębnym państwem, nie wchodziły też samodzielnie w relacje polityczne z innymi państwami, stąd nie było potrzeby tworzenia nazw dotyczących państwowości. Nazwa государыня ogólnie odnosi się do każdej kobiety sprawującej władzę na szczeblu państwowym, choć w Rosji odnoszono tę nazwę zwykle do carycy. W kaszubskojęzycznym przekładzie Bajki o rybaku i rybce, wykonanym przez Ceynowę, odnajdujemy uszczegółowienie nazwy rejestrowanej w rosyjskim pierwowzorze; kaszubski tłumacz rzeczownik государыня przetłumaczył jako królevjąnka, czyli 'królewna'. Mamy tu zatem do czynienia z przesunięciem znaczeniowym, ponieważ ogólna nazwa государыня, odnosząca się do jakiejkolwiek kobiety sprawującej władzę państwową, została zawężona do nazwy królevjąnka, oznaczającej kobietę sprawującą władzę w królestwie.

Kolejnym wyrazem zakorzenionym w kulturze rosyjskiej, a notowanym w pierwowzorze Bajki o rybaku i rybce, jest rzeczownik бояре (wersy: 151, 162), tłumaczony na język polski jako bojarzy. Bojarami określało się szlachtę feudalną, magnatów, wielkich właścicieli ziemskich na Rusi (Кузнецов (red.) 2007, s. 53). Rekrutowali się oni spośród członków drużyny książęcej, a także lokalnej administracji. Służyli księciu, a ten rozdzielał między nich dobra ziemskie, choć w skład ich majątków wchodziły też często ziemie zagarnięte chłopom (Bazylow 1985, s. 36). W późniejszym czasie najbardziej wpływowi bojarzy współrządzili państwem, zasiadając w Dumie Bojarskiej, która była organem doradczym wielkiego księcia, a potem cara (Зимин 1988). Typowe dla nich było to, że nie golili oni bród oraz nosili długie szaty. Tytuły bojarskie były nadawane w Rosji do czasów Piotra Wielkiego, który je zniósł, likwidując zarazem organ, jakim była Duma Bojarska (Bazylow 1985, s. 191). W kaszubszczyźnie nie mamy ani językowego, ani tym bardziej kulturowego ekwiwalentu rosyjskiej nazwy бояре. Florian Ceynowa w swojej translacji bajki Puszkina omawiany tu rzeczownik przetłumaczył jako panovje. Wyraz pan dawniej na Kaszubach, podobnie zresztą jak w polszczyźnie, był nie tylko formą grzecznościową, ale oznaczał też dziedzica, gospodarza, pana domu, chlebodawcę (Sychta 1965-1976, t. IV, s. 19-20). Oczywiście, nie jest to właściwy odpowiednik rosyjskiej nazwy бояре. Tłumacz znów dokonał adaptacji, próbując dostosować realia rosyjskie do kultury i wiedzy czytelnika pochodzą- 
cego z Kaszub. Jednocześnie adaptując nazwę silnie zakorzenioną w rosyjskiej kulturze, jaką jest rzeczownik бояpe, tłumacz dokonał pewnych przesunięć semantycznych w kaszubskojęzycznym przekładzie.

Uwarunkowane kulturowo zmiany językowe w kaszubskim przekładzie $B a j$ ki o rybaku i rybce Puszkina dotyczą nie tylko przesunięć znaczeniowym poszczególnych słów i wyrażeń, ale obejmują też poszukiwanie ekwiwalentów związków frazeologicznych. Problem tłumaczenia frazeologizmów zostanie omówiony na jednym - moim zdaniem, najciekawszym — przykładzie. W pierwowzorze bajki pojawił się frazeologizm белены объелся. Definicja wymienionej jednostki w słowniku frazeologicznym jest następująca: 'обезумел, одурел', со należy przełożyć na język polski jako 'oszalał', w zacytowanej pracy leksykograficznej omawiany frazeologizm klasyfikowany jest jako potoczny i wulgarny (Молотков (red.) 2001, s. 272). Wymienionego zwrotu frazeologicznego można użyć, gdy ktoś jest zszokowany poczynaniami jakiegoś człowieka, a zachowanie tej osoby wydaje się dziwaczne i niecodzienne. Należy nadmienić, że белена to roślina zielna z rodziny psiankowatych, znana w języku polskim pod nazwą lulek. Występuje ona w Europie, Azji, w Ameryce Północnej i Południowej oraz w Australii, jednak szczególną popularność ziele to zyskało w Rosji (Танфильев 1890-1907, t. V, s. 182). Wszystkie części lulka, także nasiona przypominające wyglądem ziarenka maku, są trujące. Zjedzenie ich powoduje zawroty głowy, rozszerzenie źrenic, senność, wymioty; ponadto człowiek, który spożyje ziarenka lulka, może być nienaturalnie pobudzony oraz doświadczać halucynacji i majaków, tym samym przypomina on kogoś, kto stracił rozum, a jego zachowanie wydaje się nieadekwatne, w ostateczności osoba ta może nawet umrzeć (Вавилов (red.) 1949-1958, t. IV, s. 417). Te przypominające szaleństwo objawy chorobowe, które powoduje spożycie lulka, stały się podstawą do utworzenia rosyjskiego zwrotu frazeologicznegо белены объелся.

Fraza ta nie ma ekwiwalentu o podobnej strukturze w kaszubszczyźnie. Na Kaszubach (a także w całej Polsce) lulek nie jest tak popularny, jak na obszarze rosyjskim, a poza tym - jako roślina słabo rozpoznawalna na tym obszarze nie funkcjonuje on w żadnych frazeologizmach. Dlatego tłumacz bajki Puszkina na język kaszubski musiał znaleźć inny ekwiwalent rosyjskiego zwrotu frazeologicznego. Mógł on albo przełożyć go opisowo, albo poszukać w kaszubskiej frazeologii adekwatnego zwrotu, jednakże wpisanego w kulturę Kaszub. Florian Ceynowa wybrał tę drugą drogę i szukał na gruncie tradycji kaszubskiej odpowiednika, który miał być znaczeniowo koherentny z formą użytą w pierwowzorze. W oryginalnym tekście bajki omawiany tu frazeologizm pojawił się $\mathrm{w}$ takim kontekście: Что mы, баба, белены объелась? (125 wers) - cały ten zwrot został przetłumaczony na język kaszubski następująco: Babo, gvésno Ce wugrézła gzika! Rzeczownik gzyk (gzik), używany też w formie żeńskiej gzyka, ma w kaszubszczyźnie wiele znaczeń - w sensie podstawowym wyraz ten oznacza 'małego gza', owada z rodziny gzowatych, nazywanego też w polszczyźnie gzikiem. 
Ponadto słowo to bywa używane w znaczeniu 'reumatyzm', a także wtórnie jako neosemantyzm otrzymało ono znaczenie 'samolot'. Jest jeszcze czwarte, metaforyczne znaczenie tego leksemu, mianowicie 'obłęd' - z tym ostatnim rozumieniem omawianego tu rzeczownika związane są następujące frazeologizmy: miec gzyka i miec gzyka w głowie — 'być szalonym', dostac gzyka — 'zwariować, być narwanym'. Jak widać, ostatni z użytych zwrotów odpowiadałby znaczeniowo rosyjskiej frazie белены объелся i najpewniej intencją Ceynowy było wyrażenie w swoim tłumaczeniu takiego właśnie znaczenia. Jednakże tłumacz użył innego zwrotu frazeologicznego ce wugrézła gzika (znanego też jako kasył ce gzyk), który semantycznie nie odpowiada rosyjskiemu pierwowzorowi, tak można wyrazić się bowiem o człowieku obrażonym, a nie szalonym (Sychta 1965-1976, t. I, s. 397). Zmiana frazeologizmu w translacji Bajki o rybaku i rybce motywowana była kulturowo, wynikała stąd, że roślina белена nie jest zakorzeniona w tradycyjnej kulturze kaszubskiej, nazwa tego ziela nie wchodzi też w skład żadnych znanych na Kaszubach frazeologizmów odnoszących się do bycia szalonym. Dlatego też tłumacz bajki Puszkina na język kaszubski w zasobach języka kaszubskiego poszukiwał adekwatnego frazeologizmu, który wyrażałby podobne znaczenie. Najpewniej przez nieuwagę bądź też niewiedzę użył on zwrotu o innym znaczeniu, który jednak strukturalnie był podobny do kaszubskojęzycznego frazeologizmu oznaczającego popadanie w obłęd.

Wszystkie opisane wyżej przykłady pokazują, że autor kaszubskiego tłumaczenia Bajki o rybaku i rybce Aleksandra Siergiejewicza Puszkina w swojej translacji starał się przyjmować strategię adaptacji, pozbawiając tekst kulturowych sygnałów obcości. Znaczenia słów, będących w pierwowzorze nośnikami rosyjskiej tradycji i kultury, uległy daleko idącym modyfikacjom. Dzięki przesunięciom znaczeniowym zastosowane w przekładzie słownictwo nie wywołuje skojarzeń z obcą, nieznaną kaszubskiemu czytelnikowi kulturą. Zmiany językowe w zakresie frazeologii również sprawiają, że kaszubskojęzyczny tekst bajki Puszkina zostaje kulturowo przyswojony przez tradycję Kaszub. Realia właściwe kulturze Rosji zostały z tekstu przekładu wyeliminowane i zastąpione odpowiednikami rodzimymi, właściwymi dla kaszubszczyzny, choć nie zawsze do końca adekwatnymi. Transformacje kulturowe w przekładzie Bajki o rybaku i rybce pociągają za sobą nieodzowne zmiany językowe. Porównanie pierwowzoru bajki Puszkina i jego kaszubskojęzycznego przekładu pozwala dostrzec różnice kulturowe i odmienny obraz postrzegania rzeczywistości przez Rosjan i Kaszubów. Przyjęta przez autora translacji strategia przyswojenia kolorytu lokalnego przez jego adaptację zorientowana jest przede wszystkim na odbiorcę dzieła przekładanego, który ma mieć do czynienia z tekstem odpowiadającym jego kulturze, tradycji i wiedzy o świecie. Wyeliminowanie z kaszubskiej wersji Bajki o rybaku i rybce sygnałów obcości ma służyć lepszemu, nienaznaczonemu egzotycznością, odbiorowi dzieła przez kaszubskojęzycznego czytelnika. 


\section{Bibliografia}

Bazylow L. (1985), Historia Rosji, Wrocław.

Ceynowa F. (1986), Wò rébôku é ribce, „Skôrb Kaszébsko-słovjnskjé mòvé”, nr IX, s. 128-132.

Kielar B.Z. (1988), Ttumaczenie i koncepcje translatoryczne, Wrocław.

Krysztofiak M. (2011), Translatologiczna teoria i pragmatyka przekładu artystycznego, Poznań.

Lewicki R. (2000), Obcość w odbiorze przekładu, Lublin.

Sychta B. (1965-1976), Stownik gwar kaszubskich na tle kultury ludowej, t. I-VII, Wrocław.

Whorf B.L. (2002), Język, myśl i rzeczywistość, przeł. T. Hołówka, Warszawa.

Андреева Р.П. (1997), Энииклопедия моды, Санкт-Петербург.

Вавилов С.И. (red.) (1949-1958), Большая советская энциклопедия, t. 1-51, Москва.

Зимин А.А. (1988), Формирование боярской аристократии в России во второй половиние $X V$-первой трети XVI в., red. В.И. Буганов, Москва.

Кузнецов С.А. (red.) (2007), Современный толковый словарь русского языка, Санкт-Петербург.

Молотков А.И. (red.) (2001), Фразеологический словарь русского языка, Москва.

Танфильев Г.И. (1890-1907), Белена, [w:] Энииклопедический словарь Брокгауза и Ефрона, t. V, Санкт-Петербург, s. 182.

\section{Culturally conditioned linguistic changes in the Kashubian translation of Alexander Sergeyevich Pushkin's The Tale of the Fisherman and the Fish}

\section{Summary}

In the article I discuss the culturally conditioned linguistic changes that were recorded in the Kashubian translation of Alexander Sergeyevich Pushkin's The Tale of the Fisherman and the Fish, made in 1868 by Florian Ceynowa. The analysis has shown that the author of the translation in the Kashubian version of the fairy tale consistently applied the strategy of adaptation, eliminating any culturally foreign elements from the text. The meaning of the words which were originally carriers of the Russian culture, have been modified, so that they do not evoke associations with the Russian culture. The changes in phraseology cause the Kashubian reader to have no impression of communing with the text embodied in a different culture. The realities characteristic for the Russian culture have been replaced by native, yet not always entirely adequate, Kashubian counterparts in the translation.

Keywords: linguistic changes, translation, the Russian culture, the Kashubian culture, Pushkin 